DOI: $10.20396 /$ cel.v61io.8653465

(c) $(1)(8)$

\title{
POR UMA ANÁLISE DO DISCURSO "REVOLUCIONÁRIO" EM PICHAÇÕES
}

\author{
(FOR AN ANALYSIS OF THE REVOLUTIONARY DISCOURSE IN \\ GRAFFITI) \\ JOÃO KOGAWA ${ }^{1}$ \\ PATRÍCIA BUCIOLI KNETSCH${ }^{2}$
}

\begin{abstract}
RESUMO: Este trabalho propõe uma análise discursiva de pichações. Nosso corpus contempla pichações que tematizam o sujeito feminino e esquematizam, para esta posição, lugares a serem ocupados. Com base nos conceitos de pré-construído, interdiscurso e memória discursiva, este artigo levanta as seguintes questões: será que a pichação é, no que concerne aos significados que mobiliza, efetivamente subversiva? Seria possível haver traços de conservadorismo nessa prática? Entendemos haver um descompasso entre a prática discursiva e o conteúdo semântico mobilizado na rede parafrástica dos enunciados.

Palavras-chave: Pré-construído; interdiscurso; pichação.
\end{abstract}

ABSTRACT: This work proposes a discursive analysis of graffiti. The corpus is composed of graffiti about female questions in which is possible to outline, from the female position, places to be occupied. Based on the concepts of pre-constructed, interdiscourse and discursive memory, this article discusses the following questions: Is graffiti effectively subversive as it is described? Would it be possible to find some traces of conservatism discourse instead? We observed that there is a mismatch between discursive practice and the semantic content in the paraphrastic network of statements.

Keywords: Pre-constructed; interdiscourse; graffiti.

\section{INTRODUÇÃO}

A pichação é considerada, tanto por seus autores quanto por grande parte da sociedade brasileira, como uma prática subversiva que contraria o status quo. Seus praticantes, que aparecem aqui e ali em programas de televisão e documentários, afirmam discordar de um estado atual de coisas, valores, pensamentos, práticas culturais. Em linhas gerais, a pichação e o pichador seriam uma espécie de "grito de liberdade" contra o conservadorismo elitista das grandes cidades.

No exercício desta prática, uma série de objetos é construída com ênfase em questões sociais das mais diversas. Neste artigo tomamos como fio norteador o

${ }^{1}$ Universidade Federal de São Paulo (UNIFESP), São Paulo, SP, Brasil. mmkogawa@gmail.com https://orcid.org/0000-0001-8285-9932

${ }^{2}$ Universidade Federal de São Paulo (UNIFESP), São Paulo, SP, Brasil. pat.bucioli@gmail.com 
modo como o sujeito feminino, em especial, a mulher, é referido em alguns pichos feitos na região da grande São Paulo. Em tese, as pichações corresponderiam a um discurso contraventor e, dessa feita, contradiriam valores ideológicos dominantes sobre as mulheres na sociedade. Nesse sentido, as três formulações que analisaremos aproximam-se do discurso feminista na medida em que reivindicam, para as mulheres, uma posição de protagonista no panorama social.

Apesar desta evidência elementar - "pichar é contradizer" - e de uma suposta onipresença da contravenção, o discurso conservador está ambiguamente marcado nos três pichos analisados adiante. Ao invés de estabelecer um lugar novo e condições inéditas para as mulheres, as formulações a seguir - apesar de toda uma "vontade de verdade revolucionária" - organizam-se em torno de uma memória conservadora que poderia ser sistematizada pelo seguinte enunciado de base: (i) Toda mulher é/deve ser mãe.

Nesse sentido, este artigo segue o seguinte roteiro. Primeiramente, esboçamos uma oposição entre pichação e grafite, pois, este último pode ser considerado legal e, em certo sentido, ser pouco ou nada contraventor. A contravenção estaria inequivocamente associada à pichação, que é contrária à lei, não autorizada, espontânea e inesperada. Em seguida, construímos uma base teórica que mobiliza os conceitos de pré-construído, interdiscurso e memória discursiva para fundamentar nossa hipótese de que aquilo que se apresenta como revolucionário produz efeitos de sentido conservadores pela retomada de valores atinentes ao que o status quo dita para as mulheres. Por último, empreendemos a análise discursiva de três pichos (formulações) colhidos na região da Grande São Paulo.

\section{PICHAÇÃO/GRAFITE VERSUS GRAFITE AUTORIZADO}

Segundo Orlandi (2004, p. 98), "Não há cidade sem pichação, sem grafite atualmente. O grafite, a pichação, por sua vez são discursos da cidade em que a letra - a grafita - em sua materialidade é a ordem própria discursiva que significa pelo (por ser) urbano". Nesse panorama urbano das grandes cidades, coexistem três formas correlatas de intervenção nos muros públicos e privados: a pichação/ grafite e o grafite autorizado. A ilegalidade das primeiras está intrinsecamente relacionada à sua condição de prática contraventora enquanto, a legalidade do segundo, relativiza ou elimina essa condição. Souza (2007) afirma que a pichação está relacionada à escrita enquanto o grafite está ligado à pintura, gravura e representação plástica da imagem. Nessa mesma linha de argumentação, Gitahy (1999, p. 20) afirma que

Tanto o graffiti como a pichação usam o mesmo suporte - a cidade - e o mesmo material (tintas). Assim como o graffiti, a pichação interfere no espaço, subverte valores, é espontânea, gratuita e efêmera. Uma das diferenças entre o graffiti e a pichação é que o primeiro advém das artes plásticas e o segundo da escrita, ou seja, o graffiti privilegia a imagem; a pichação, a palavra e/ ou letra. 
Deduzimos da leitura desses autores que o grafite tem um apelo estético e refinamento no trato formal enquanto a pichação não tem grandes desenvolvimentos formais como o grafite. Por sua condição formal, pichações são marcadas por traços rápidos e apressados feitos com tinta spray, sem apelo estético e visual; já o grafite se comunica com o espaço urbano ao seu redor sob a forma de painéis coloridos feitos com tinta spray. Estes painéis são trabalhados plasticamente e há neles maior rigor no tratamento estético-visual (SOUZA, 2007).

A essa diferença formal, acrescenta-se uma outra de caráter legal que complexifica o contraste. Com efeito, no âmbito do grafite, há os que são legais e autorizados e os que não são. Assim, apesar de formalmente parecidos, do ponto de vista da posição sujeito do enunciado, o grafiteiro tanto pode ser o artista quanto o criminoso, a depender de sua categorização à luz do discurso jurídico. A tipificação legal delimita duas posições sujeito nas duas diferentes práticas: (i) o criminoso marca posição na pichação e no grafite não autorizado e o (ii) artista inscreve-se no grafite autorizado. Discursivamente, isso coloca em suspenso a pessoa física que pratica a ação. Uma mesma pessoa pode ser "criminosa" ou "artista", a depender do tipo de manifestação em que figure como autora.

Esta diferença ganhou bastante notoriedade no ano de 2017 durante a investida contra a pichação por João Dória. O prefeito da cidade de São Paulo sancionou uma lei contra a pichação e prometeu "tolerância zero" contra pichação e grafites não autorizados ${ }^{3}$. Na Lei Municipal no 16612 de 20/02/2017, destacamse os seguintes pontos:

Parágrafo único. Constitui objetivo do programa de que trata o "caput" deste artigo assegurar, dentre outros: (...)V - reconhecer a prática do grafite como manifestação artística e cultural. (...) Art. $3^{\circ}$ Para fins de aplicação desta lei, considera-se ato de pichação riscar, desenhar, escrever, borrar ou por outro meio conspurcar edificações públicas ou particulares ou suas respectivas fachadas, equipamentos públicos, monumentos ou coisas tombadas e elementos do mobiliário urbano. Parágrafo único. Ficam excluídos do programa instituído por esta lei os grafites realizados com o objetivo de valorizar o patrimônio público ou privado mediante manifestação artística, desde que consentida pelo proprietário e, quando couber, pelo locatário ou arrendatário do bem privado e, no caso de bem público, com a autorização do órgão competente e a observância das posturas municipais e das normas editadas pelos órgãos governamentais responsáveis pela preservação e conservação do patrimônio histórico e artístico ${ }^{4}$ :

Isso gerou um sem número de polêmicas em matérias de jornais e revistas. A revista CartaCapital, por exemplo, emergiu como representativa de uma posição contrária à diferenciação entre pichação e grafite, mais particularmente, no que dizia respeito à criminalização da primeira e do segundo em caso de grafitagem sem autorização. $\mathrm{O}$ argumento construído em uma reportagem escrita por Ingrid Matuoka - com as vozes de importantes representantes de movimentos de pichadores - aponta que muitos dos grafiteiros que hoje são reconhecidos como

${ }^{3}$ Disponível em: https://www1.folha.uol.com.br/cotidiano/2017/02/1860352-doria-sancionalei-anti-pichacao-e-veta-ate-grafite-nao-autorizado.shtml.

${ }^{4}$ Disponível em: https://www.legisweb.com.br/legislacao/?id=337862. Sublinhamos o trecho recorrente nas duas leis (Federal e Municipal) para demonstrar a semelhança na tipificação do grafiteiro autorizado. 
artistas, começaram como pichadores: "Hoje, Kobra expõe suas obras também no exterior, e se tornou um nome famoso, mas começou sua carreira como pichador, no Campo Limpo, zona sul de São Paulo, e foi preso mais de dez vezes" ${ }^{5 "}$.

Na mesma entrevista, Pagu, produtor de arte de rua em São Paulo diz que o grafite existe mesmo antes da rua, ele está em todo o planejamento: "Pergunte ao chefe de segurança do Estado como é frustrante lidar com elementos surpresa, com uma manifestação de rua sem regras, sem hora marcada, sem comando, sem articulação" ${ }^{6 "}$. Para ele o grafite não é apenas ilegal, mas também é algo que não quer ser legalizado; querer colocar regras e leis na arte do grafite vai contra os princípios desta modalidade ${ }^{7}$.

Um dos pontos interessantes desta e de outras matérias da mídia é que a polêmica emergiu como se fosse algo recente, como "coisa de São Paulo" e com a figura de Dória como novidade. Isso se produziu um pouco em toda a parte nos jornais do estado. Um enunciado prototípico do fenômeno pode ser parafraseado como: "A lei antipichação de João Dória". No texto da CartaCapital, a imbricação de posicionamentos composta pela fala da jornalista e dos grafiteiros/pichadores é particularmente relevante nesse sentido porque produz com mais ênfase que outros meios de comunicação a ideia de que é "o prefeito tucano" com sua lei quem promove a cisão entre grafite e pichação. Além disso, associa-se à "lei de Dória”, com sua divisão, uma espécie de segregação racial: "A busca por dividir a arte de rua tem também um recorte racial ${ }^{8 "}$.

No entanto, a "lei de Dória" - e a divisão entre pichação x grafite -, paradoxalmente, não é propriamente uma novidade na esfera legal - apesar do efeito produzido pelas recorrentes polêmicas de 2017 -, mas a implementação de uma lei Federal já em vigor desde 2011. O texto das duas leis, inclusive, é parecido em alguns pontos:

Art. 65. Pichar ou por outro meio conspurcar edificação ou monumento urbano: Pena - detenção, de 3 (três) meses a 1 (um) ano, e multa. § 1 - Se o ato for realizado em monumento ou coisa tombada em virtude do seu valor artístico, arqueológico ou histórico, a pena é de 6 (seis) meses a 1 (um) ano de detenção e multa. $\S 2^{\circ}$ Não constitui crime a prática de grafite realizada com o objetivo de valorizar o patrimônio público ou privado mediante manifestação artística, desde que consentida pelo proprietário e, quando couber, pelo locatário ou arrendatário do bem privado e, no caso de bem público, com a autorização do órgão competente e a observância das posturas municipais e das normas editadas pelos órgãos governamentais responsáveis pela preservação e conservação do patrimônio histórico e artístico nacional ${ }^{9}$.

${ }^{5}$ Disponível em: https://www.cartacapital.com.br/sociedade/na-repressao-de-doria-contraarte-de-rua-alvo-e-a-juventude-periferica.

${ }^{6}$ Disponível em: https://www.cartacapital.com.br/sociedade/na-repressao-de-doria-contra-artede-rua-alvo-e-a-juventude-periferica.

${ }^{7}$ Disponível em: https://www.cartacapital.com.br/sociedade/na-repressao-de-doria-contra-artede-rua-alvo-e-a-juventude-periferica.

${ }^{8}$ Disponível em: https://www.cartacapital.com.br/sociedade/na-repressao-de-doria-contra-artede-rua-alvo-e-a-juventude-periferica.

${ }^{9}$ Disponível em: http://www.planalto.gov.br/ccivil 03/Ato2011-2014/2011/Lei/L12408.htm. Sublinhamos o trecho recorrente na Lei Municipal "criada" por João Dória. 
Em contraposição a esta tipificação legal, os pichadores apresentam-se como transgressores por meio da intervenção ilegal - eles mesmos primam por essa condição - de sua marca nos muros e monumentos históricos. Conforme Gitahy (1999, p. 23), "Pichação e graffiti têm sempre algo em comum, carregam em si a transgressão [...]".

Em uma entrevista ao apresentador Serginho Groisman no quadro Qual É? do programa Altas Horas ${ }^{10}$, um grupo de pichadores debate as motivações do picho e uma das primeiras afirmações de Djan, um dos pichadores entrevistados, é que assim como o monumento tem uma representação histórica e remete à memória local, os pichadores também buscam se aproximar e fazer parte da história da cidade eternizando a sua marca. Isto é, a ocupação do espaço urbano é uma questão fundamental para os pichadores e, de certa forma, é o que define a pichação como contraventora. Bruno e Djan dizem que dentro da comunidade dos pichadores existe uma rivalidade embasada predominantemente em ocupação territorial. Evidencia-se nas falas do grupo entrevistado que a ilegalidade dessa ocupação é reivindicada. Para eles o muro é uma agressão física e o picho uma agressão estética.

Há ainda outro acordo no grupo a respeito da motivação do ato. Jaqueline, quando perguntada sobre por que decidiu ser pichadora, diz: "sempre tive um tipo de revolta, um tipo de implicância, então eu sempre procurei descontar, vamos se dizer, na sociedade ${ }^{11}$ '. Djan ainda comenta a relação entre o picho versus grafite e, para ele, o parâmetro do respeito na rua é a transgressão. Se o grafite foi feito de forma ilegal, é respeitado. Ele completa dizendo que o problema do grafite é que ele se tornou um antídoto contra a pichação.

O pichador ele é um artista, mas um artista diferente dos outros. Nós somos artistas libertários, transgressivos e revolucionários, entendeu? $\mathrm{O}$ reconhecimento que a gente busca é pela marginalidade. (...) A gente também entende quem não gosta, quem não aceita ... ninguém é obrigado a aceitar o picho. (...) quando vão construir um prédio, um estádio, um shopping, ninguém consulta a população, as pessoas não têm participação na construção da cidade, e ficam revoltadas com o picho que é uma intervenção efêmera. Um prédio vai durar para sempre; um prédio na frente da janela da sua casa... nunca mais vai bater o sol lá, o picho não, ele pode ser facilmente removido ${ }^{12}$.

Isto é, o posicionamento oficial a respeito da pichação é justamente o de ser transgressora, subversiva e esta transgressão está identificada com atuar em local proibido. Em certo sentido, a pichação é uma "forma pela forma" em local proibido. A mensagem transgressora tem menos a ver com o conteúdo pichado embora isso também seja considerado - do que com a visibilização "da rabisqueira" nos muros da cidade. De acordo com Orlandi (2004, p. 98), em uma concepção de grafite próxima ao que Souza (2007) e Gitahy (1999) definem como pichação,

\footnotetext{
${ }^{10}$ Disponível em: https://globoplay.globo.com/v/3353635/.

${ }^{11}$ Disponível em: https://globoplay.globo.com/v/3353635/.

${ }^{12}$ Disponível em: https://globoplay.globo.com/v/3353635/.
} 
O caráter indecifrável do grafite é sua marca, parte de seu modo de significar o não-sentido (non-sense). Ele joga sobre isso, fazendo dessa sua forma enigmática seu modo de significar o in-significante. E aí encontramos o laço com o comum, o popular, que se reparte em grupos de outra maneira. Novas formas de significação, novas organizações do dizer, novos modos de entrar nos processos de identificação. Outras formas de subjetivação.

Essa identidade entre grafite e pichação ganha vez na opinião do grafiteiro Rui Amaral - artista plástico e um dos precursores do grafite em São Paulo:

"Eu entendo grafite e pichação como uma coisa só", explica Rui Amaral. "O que importa é a atitude, o que te leva a fazer isso, não o que você escreve. A gente quer que as pessoas entendam a importância da arte urbana livre para a luta por direitos. E um deles é o direito de se expressar ${ }^{13 \%}$.

Obviamente, estamos falando aqui de "pichadores profissionais" com metas e plano de organização definidos. Retomando Djan: "Tem grupos e tem pessoas individuais. Tem muitos pichadores que sonham em ser de uma união dessa, de um Círculo Vicioso, dos Mais Fortes, do T13... É igual futebol. Você começa jogando nos times pequenos e um dia você quer chegar num time grande ${ }^{14}$.

No entanto, apesar dessa centralização em grupos oficiais e famosos, há as pichações avulsas, ou seja, aquelas feitas sem um vínculo com grupos e sem uma assinatura reconhecida no meio. É destas que nos ocupamos aqui. A representatividade desta marca deixada em um espaço público nas pichações que analisaremos tornam visíveis reivindicações do/para o sujeito feminino. $A$ priori, por serem pichações, essas formulações são lidas como contravenção a um discurso machista conservador. Em certo sentido, efetivamente, elas o são. No entanto, como demonstraremos, há algo que falha aí. Ao mesmo tempo em que denunciam a opressão à mulher, os pichos fortalecem o conservadorismo e o papel de mãe que "toda mulher ocupa ou deve ocupar".

Se o que importa é a prática e não o que se escreve, para retomarmos a fala de Amaral mais acima, há aí, entre o "pichar" e o "pichado", uma ruptura, um efeito de desidentificação entre o picho como prática discursiva e o pichado como resultado dessa prática. Abre-se assim, no espaço da pichação, a possibilidade para o conservador, para o status quo, para a reafirmação daquilo que se pretende questionar.

\section{BASES PARA UMA REFLEXÃO: PRÉ-CONSTRUÍDO, INTERDIS- CURSO E MEMÓRIA DISCURSIVA}

As pichações, a priori, conforme demonstramos pelas falas dos próprios pichadores em posicionamentos na mídia, são tidas como contraventoras. Isto está atrelado à sua condição de ilegalidade na legislação brasileira e também ao desejo

${ }^{13}$ Disponível em: https://www.cartacapital.com.br/sociedade/na-repressao-de-doria-contra-artede-rua-alvo-e-a-juventude-periferica.

${ }^{14}$ Disponível em: https://globoplay.globo.com/v/3353635/. 
de ilegalidade preconizado pelos próprios movimentos de pichadores dos quais recuperamos algumas falas anteriormente. No entanto, há uma diferença entre as marcas deixadas nas paredes e seu significado quando se lê o que está escrito. Entre a forma e o conteúdo, pode haver - e há, como demonstraremos a seguir - uma ruptura entre o caráter subversivo de uma prática e aquilo que esta prática produz como texto, ou seja, como produto desta subversão.

A partir do corpus selecionado - composto por três formulações-picho que tematizam a mulher e sua relação com a maternidade -, percebemos que a subversão e o conservadorismo convergem pela retomada de uma memória da mulher como mãe sob a forma de pré-construídos. De acordo com Courtine (2009, p. 74), "O pré-construído remete assim às evidências pelas quais o sujeito se vê atribuir os objetos de seu discurso: 'o que cada um sabe' e simultaneamente 'o que cada um pode ver' em uma dada situação".

De acordo com Pêcheux (1997, p. 111), o pré-construído “[...] dá seu objeto ao pensamento sob a modalidade da exterioridade e da pré-existência" (Pêcheux, 1997, p. 111). As pichações são, paradoxalmente, um misto de quebra de paradigma e manutenção de uma ordem que se fundamenta no jogo entre a memória e o esquecimento, entre o novo e o antigo, a mudança e a tradição:

Citação, recitação, formação do pré-construído: é assim que os objetos do discurso, dos quais a enunciação se apodera para colocá-los sob a responsabilidade do sujeito enunciador, adquirem sua estabilidade referencial no domínio de memória como espaço de recorrência das formulações (Courtine, 1999, p. 20).

Há, desse modo, dois vetores atuando na memória: (i) o primeiro define a pichação como prática e delineia a presença do anti-machismo e do anticonservadorismo nas formulações-picho. Este vetor desestabiliza a regularidade garantida pela lei inserindo valores contraventores; (ii) o segundo, exclusivamente associado aos sentidos do texto pichado, delineia a presença do machismo e do conservadorismo que, em tese, pretende desconstruir. Esse outro vetor da formulação-picho mantém estável uma regularização pré-existente. Nas palavras de Orlandi (2004, p. 48),

Se, do ponto de vista linguístico o pré-construído responde a formas sintáticas (como o encaixe, as normalizações, as construções com epítetos), apresentando um elemento como se já estivesse lá, do ponto de vista discursivo, mostra que sempre há a relação com um elemento prévio ao discurso, não asseverado pelo sujeito, não submetido à discussão, já esquecido em sua origem e que, no entanto, funciona no dito. (...) O que nos leva a pensar a ligação entre o estereótipo e o pré-construído, vendo o estereótipo, o lugar comum, como o traço de discursos e de julgamentos prévios, comuns, cuja origem já está apagada na formulação particular, individual.

A estrutura de nossas formulações, desse modo, ainda que não recortemos uma construção linguística de tipo "encaixe" ou "epíteto", guia-nos por um jogo intrincado entre o dito e aquilo que lhe dá sustentação, ou seja, os elementos préconstruídos, do ponto de vista discursivo, que funcionam como "naturais" ao papel da mulher na sociedade através dos séculos: 
É preciso, pois, educar as meninas, e não exatamente instruí-las. Ou instruí-las apenas no que é necessário para torná-las agradáveis e úteis: um saber social, em suma. Formá-las para seus papéis futuros de mulher, de dona-de-casa, de esposa e mãe" (PERROT, 2007, p. 93).

Dessa forma, os efeitos de sentido ambíguos que se estabelecem entre o revolucionário e o conservador assentam-se sobre uma rede de valores que garantem a "naturalidade" do estereótipo (ORLANDI, 2004) que podemos elucidar - no que concerne especificamente às mulheres - com a afirmação de Perrot. A coexistência da contravenção com a manutenção do status quo é sustentada por lugares-comuns associados à condição feminina. Os efeitos de sentido de "ser mãe" recorrentes nas formulações-picho configuram uma "evidência" sobre a mulher que perdura, de modo conservador, através de diferentes temporalidades (PERROT, 2007). Esta permanência, que pode ser sintetizada sob a forma do enunciado de referência "Toda mulher é/deve ser mãe", é regulada por uma rede interdiscursiva que mobiliza o religioso, o político, o biológico e inscreve este microuniverso das pichações no espaço do "dizer o mesmo", apesar da forma contraventora mobilizada para tanto. Isso nos remete à seguinte afirmação de Pêcheux:

[...] todo enunciado é intrinsecamente suscetível de tornar-se outro, diferente de si mesmo, se deslocar discursivamente de seu sentido para derivar para um outro (...). Todo enunciado, toda sequência de enunciados é, pois, linguisticamente descritível como uma série (léxicosintaticamente determinada) de pontos de deriva possíveis, oferecendo lugar à interpretação. É nesse espaço que pretende trabalhar a análise de discurso. (PÊCHEUX, 2015, p. 53)

Courtine defende que o interdiscurso está atrelado aos campos de saber artístico, político, religioso, publicitário -, responsáveis pela regulação das “[...] coisas-a-saber [...]" (PÊCHEUX, 2015, p. 53) em um determinado momento histórico:

[...] as 'coisas-a-saber' coexistem assim com objetos a propósito dos quais ninguém pode estar seguro de 'saber do que se fala', porque esses objetos estão inscritos em uma filiação e não são o produto de uma aprendizagem: isto acontece tanto nos segredos da esfera familiar 'privada' quanto ao nível 'público' das instituições [...]” (PÊCHEUX, 2015, p. 55),

É pelos campos de saber e suas relações com os poderes que os sujeitos são construídos e se encontram posicionados. Pêcheux (2015) também defende que todo discurso é atravessado por outro uma vez que são compostos por saberes acumulados que foram exercidos pelo interlocutor e pela retomada de dizeres antecedentes. Sempre haverá discursos amparando, fortalecendo e contestando o discurso corrente, assim como haverá transformações de sentidos igualmente transpassados por outros sentidos. Um enunciado - entendido como ponto de referência para diferentes formulações - nunca está sozinho, portanto, é necessário que o interpretemos sob a égide de seu vínculo com o interdiscurso.

Vale recuperar aqui a distinção entre enunciado e formulação proposta por Courtine (2009) a partir de Foucault. O enunciado é, ao mesmo tempo, algo dito em um determinado momento - e que faz funcionar um número de regras associadas ao dizer possível - e uma estrutura que vai servir de referência - 
espécie de modelo norteador - para formulações presentes e futuras. Trata-se de uma estrutura-tipo que servirá de "inspiração parafrástica" para incontáveis formulações - entendidas como manifestações concretas, singulares e pontuais do enunciado. Nesse sentido, o enunciado é uma espécie de "titereiro" em relação às formulações, que funcionam mais ou menos como "marionetes"; guarda uma verticalidade enquanto a formulação uma horizontalidade. Além disso, esta última está para o sujeito falante inscrito em uma sequência intradiscursiva e o primeiro está para o sujeito do saber inscrito no interdiscurso: "O sujeito do discurso é, de fato, ao mesmo tempo sujeito ideológico, na sua relação com o sujeito do saber que assegura o enunciado; e sujeito falante, por poder enunciar os elementos desse saber na formulação" (COURTINE, 2009, p. 96, grifo do autor).

O interdiscurso é histórico e linguisticamente dedutível. Ele se apresenta como conjuntos de formulações que resultam de diferentes enunciações que remetem a um domínio da memória. A memória, por sua vez, representa a possibilidade movente da manutenção/ruptura de um discurso. Para o enunciado "Toda mulher é/deve ser mãe", a formulação "Eu não vim da sua costela, você veio do meu útero", por exemplo, estabelece relação interdiscursiva perpassada por uma memória do discurso criacionista (Eva, a primeira mulher, teria sido criada a partir da costela de Adão, o primeiro homem) versus a delimitação científicobiológica a respeito da origem dos homens/seres humanos (homens não vem de costelas, mas de úteros). Considerando que um discurso incorpora rudimentos de outros discursos que transcorrem múltiplos momentos históricos e são tomados em distintas posições ideológicas, sua representação material em uma formulação torna-se, à luz da memória, uma complexa rede de atualizações e retomadas.

Se as pichações têm o revolucionário por característica determinante - as falas públicas de representantes do movimento nos meios de comunicação, inclusive, usam esse atributo como condição intrinsecamente ligada à sua existência -, a opacidade da língua conduz a falhas que abrem o revolucionário ao conservador.

Sob essa ótica, a interdiscursividade evidencia uma resistência ao conservadorismo, mas também o exercício inconsciente de sua manutenção. Se o discurso revolucionário apresenta-se nas pichações como anti-poder, isso não é um ritual isento de falhas, já que reproduz o discurso contra o qual luta:

[...] a causa que determina o sujeito exatamente onde o efeito de interpelação o captura; o que falta é essa causa, na medida em que ela se "manifesta" incessantemente e sob mil formas (o lapso, o ato falho, etc.) no próprio sujeito, pois os traços inconscientes do significante não são jamais "apagados" ou "esquecidos", mas trabalham, sem se deslocar, na pulsação sentido/non sens do sujeito dividido (PÊCHEUX, 1997, p. 300).

É nesses termos que se torna indispensável a noção de enunciado dividido. Courtine (2009) propõe uma "quebra de espelhos" na AD ao encaminhar um modo de analisar que prevê a interferência do outro no um. Nosso corpus constituise justamente dessa heterogeneidade na medida em que materializa um discurso revolucionário que "anda de mãos dadas" com o discurso conservador. É esse efeito de ruptura ou de quebra de aliança que justifica a retomada do conceito de enunciado dividido, caracterizado por uma discordância interna entre posições 
sujeito que estão no interior de uma mesma formação discursiva. Nesse cenário, as formulações se apresentam em um mesmo espaço discursivo, mas provém de discursos antagônicos. Dentro dessa arena conflitante, emergem efeitos de deslizamento no jogo interdiscursivo de quebra/manutenção de uma memória:

Se uma posição de sujeito se define como uma relação de identificação do sujeito enunciador com o sujeito universal de uma FD, a especificidade da posição de sujeito no funcionamento polêmico de discurso deve-se ao fato de que essa identificação, pela qual um sujeito falante é interpelado/constituído em um sujeito ideológico, efetua-se em um lugar dividido por uma contradição (COURTINE, 2009, p. 202, grifo do autor).

Isto posto, demonstraremos, a seguir, o descompasso entre o dizer das pichações selecionadas para análise e as contradições entre os diferentes efeitos de sentido que, ora pendem para uma posição contraventora própria à pichação como prática subversiva, ora caminham para a manutenção de um discurso conservador que reitera valores patriarcais sobre a mulher.

\section{O QUE PODE FALHAR NA RELAÇÃO PICHAÇÃO $\Leftrightarrow$ CONTRA- VENÇÃO É O SIGNIFICADO}

O primeiro da série de pichos selecionados neste artigo traz a seguinte sequência linguística: "Toda mulher e mãe de todos os homens":

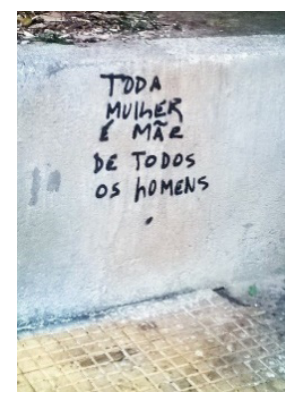

Figura 1

Fonte: Foto de Patrícia Bucioli

De início, é importante recuperarmos a ideia de "papel da mulher", que remete historicamente a uma série de acontecimentos e práticas que definiram e ainda definem, em "novos" moldes, qual é o lugar da mulher na sociedade. Nosso corpus é composto por um pré-construído que se atualiza em três pichações. $\mathrm{O}$ enunciado a que essas formulações recorrem - "toda mulher é/deve ser mãe" - reproduz valores de séculos passados - ao menos, desde a Idade Média, com variações, evidentemente - a respeito do papel da mulher na sociedade. Perrot afirma que certos papéis, dentre os quais destacam-se as ideias de passividade e receptáculo atribuídas à mulher, são reproduzidos desde a antiguidade: 
As mulheres não são apenas diferentes: modelagem inacabada, homem incompleto, falta-lhes alguma coisa, são defeituosas. A frieza da mulher se opõe ao calor do homem. Ela é noturna, ele é solar. Ela é passiva e ele, ativo. O homem é criador, por seu sopro, o pneuma, e por sua semente. Na geração, a mulher não passa de um vaso do qual se pode esperar apenas que seja um bom receptáculo. O pensamento de Aristóteles modela por muito tempo o pensamento da diferença entre os sexos, sendo retomado com modulações pela medicina grega de Galiano. E na Idade Média, pelo teólogo Tomás de Aquino (PERROT, 2007, p. 23).

Nosso objetivo não é esgotar esta matéria, mas introduzir um ponto de reflexão que sustente a ideia de que o que se apresenta nos pichos selecionados exige uma relativização na ideia de que "pichação é apenas contravenção/ revolução, portanto, resistência". Ao invés de tomarmos isso como evidência, problematizamos que "a pichação pode ser contravenção/revolução/resistência, mas também pode ser conservadorismo/manutenção/poder” (enunciado dividido). Nossa tese não invalida a ideia mais ou menos aceita de que "pichar é contraporse", apenas a relativiza.

O efeito de sentido de maternidade como "vocação feminina" tem a roupagem questionadora dos pichos, mas significados conservadores que emergem junto aos contraventores. Esse conservadorismo pode ser entendido como um retorno sutil daquilo que depreendemos da seguinte afirmação de Perrot (2007, p. 69),

A sociedade ocidental promove a assunção da maternidade. Ela é "aureolada" de amor, "o amor a mais", segundo a expressão de Elisabeth Badinter, que descreve o crescimento do sentimento maternal a partir do século XVII e o da figura da mãe, tanto nas práticas (saúde, puericultura, educação na infância) quanto na simbólica.

Guardadas as devidas singularidades históricas, não é outra a imagem que emerge na formulação "Toda mulher é mãe de todos os homens". O determinante "toda" é típico da construção de leis universais. A presença do pronome indefinido inscreve este picho em uma rede lógica a partir da qual podemos interpretá-lo como a premissa maior de um silogismo que omite a premissa menor e a conclusão, ou seja, um entimema. Nesses termos, se desenvolvêssemos o entimema sob a forma de um silogismo completo, teríamos:

\section{Toda mulher é mãe de todos os homens \\ $\mathrm{X}$ é mulher \\ $\mathrm{X}$ é mãe de todos os homens}

O entimema, como afirma Aristóteles (Retórica, I, 1357a) "[...] tem que consistir de poucas proposições, em menor quantidade frequentemente do que as que constituem um silogismo completo [...]". Outra característica do entimema é que ele apresenta uma verdade provável, não necessária, ou seja, há certo consenso - nos termos de Pêcheux (1997), um "imaginário" - que viabiliza o reconhecimento do entimema como verdade. Nosso objetivo não é fazer uma análise refinada à luz da retórica aristotélica, mas consideramos relevante oferecer a definição de entimema ao leitor na medida em que a estrutura do enunciado inscrito na pichação funciona nesse molde. Do ponto de vista lógico, portanto, a 
formulação "Toda mulher é mãe de todos os homens" não é uma verdade, já que não há relação necessária entre "ser mulher" e "ser mãe".

Podemos retomar o silogismo preenchendo a variável por um nome próprio:

Toda mulher é mãe de todos os homens

Maria é mulher

Maria é mãe de todos os homens

Verifica-se, com este preenchimento, o quanto esta formulação, do ponto de vista lógico, é insustentável. No entanto, retomando Pêcheux (1997) naquilo que ele afirma ser o "ponto cego" da teoria semântica de Frege, não podemos definir a linguagem apenas como instrumento de saturação referencial a partir de um ideal de "verdadeiro" x "falso". Antes, cumpre desenvolver um olhar discursivo que tome a metáfora e a metonímia como figuras essenciais na compreensão do atravessamento político no "imaginário", isto é, naquilo que histórica e ideologicamente é produzido como aceitável.

A esse respeito, a formulação acima funciona metonimicamente pela extensão semântica de uma qualidade, ou seja, a propriedade que a mulher tem de "ser mãe" é estendida ao universo total de mulheres. Assim, "mulher" e "mãe" formariam uma só e única classe por um efeito de generalização típico de formulações que constroem verdades universais por implicação. Retomando a fórmula utilizada por Pêcheux (1997, p. 109), teríamos: $\forall x, \alpha(x) \supset \beta(x)$, em que $x=$ seres vivos que podem gerar a vida; $\alpha=$ ser mulher; $\beta=$ ser mãe. Preenchendo a fórmula, temos a seguinte paráfrase: Para todo ser que pode gerar a vida, ser mulher contém ser mãe.

A implicatura estabelece uma relação necessária entre duas propriedades, ou seja, se é $x$, então, $y$ sob a forma de um pré-construído. O "ser mãe" emerge na formulação como uma evidência primeira para o "ser mulher" e é aí que os sentidos deslizam da contravenção - adequada à ideia geral da pichação como prática subversiva - para o conservadorismo - aquilo a que o picho não está consensualmente relacionado. Se, por um lado, a sequência linguística constrói um efeito de sentido de valorização da mulher pelo subentendido de que, se toda mulher é mãe de todos os homens, todos os homens, na condição de filhos, devem respeitar esta mulher, por outro lado, a mesma sequência linguística deixa falar certo conservadorismo que define que toda mulher é/deve ser mãe.

Cabe observar ainda que o termo "homens" é ambíguo, apesar de isso não trazer mais ou menos equívoco à proposição. Esta ambiguidade apenas contribui com dois níveis de intensidade diferentes. Quando o pronome indefinido "todo" é acompanhado do artigo "os" - em "todos os homens" - o sentido também desliza metonimicamente. Em uma das leituras possíveis, "homens" pode significar "sujeito do gênero masculino". Esse significado é mais restrito e confere ao todo da formulação um aspecto de "luta local" entre mulheres x homens. Na outra leitura possível, temos "homens" funcionando metonimicamente em relação a "humanidade". Nesse caso, não só os homens, mas toda a humanidade deveria respeitar e reconhecer a mulher, que é/deve ser mãe, como origem das coisas. 
Emerge um efeito de sentido de "pandorização", ou seja, a mulher é a causa do mundo, portanto, respeitem-na, valorizem-na.

"Mãe" produz, dessa forma, tanto um efeito de sentido de reivindicação para as mulheres quanto de manutenção do imaginário da "mãe dedicada", de "boa índole", "casada", que administra não só as tarefas do lar, mas também a educação de seus filhos e o bom relacionamento com o cônjuge. A nosso ver, esta última escala de valores está até mais disseminada que a primeira, já que, mesmo a valorização e o respeito subentendidamente reivindicados ganham força à luz do conceito de mãe no sentido tradicional e conservador do termo. Parafrasticamente, podemos entender a formulação nos seguintes termos: "Toda mulher é mãe; todos os homens têm mães; logo, toda mulher deve ser respeitada". O não-dito subjacente ao pré-construído, como afirmamos acima, é uma condicionante quase universal de natureza conservadora: toda mulher é/deve ser mãe.

Exatamente pelo fato de ser considerada o centro das relações familiares, a convenção social é de que qualquer tipo de ato contra a figura materna deve ser evitado, desde palavras ofensivas até ataques físicos. O enunciado produz ainda outro efeito de sentido pelo não-dito: desrespeitar/agredir/ofender uma mulher pode, mas se ela for mãe, não. Essa possibilidade interpretativa coloca em cena uma outra rede parafrástica, muito utilizada quando, por exemplo, em notícias de agressão à mulher, se diz algo do tipo: "Esse sujeito que faz isso com uma mulher não tem mãe?", ou, "Gostaria de saber se esse sujeito gostaria que se fizesse isso à mãe dele". Assim, nessa rede de sentidos em que a formulação parece denunciar, subentendidamente, as violências contra a mulher, a palavra "mãe" é a atenuante e também a reafirmação de um machismo sistêmico.

A formulação seguinte, que também participa da construção do sujeito feminino como mãe, estrutura-se da seguinte forma:

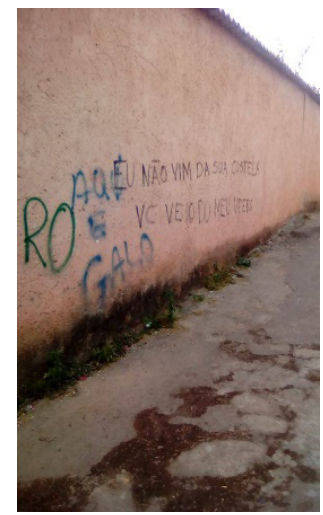

Figura 2. Eu não vim da sua costela. Você veio do meu útero Fonte: Olhe os muros $^{15}$

${ }^{15}$ Disponível em: https://www.facebook.com/olheosmuros/photos/a.279245768753490/168414 $\underline{5391596847 / \text { type }=3}$ 
Há, inicialmente, um efeito de diálogo simulado em que o picho aparece como resposta a uma afirmação. A afirmação pode ser deduzida por um acesso à interdiscursividade em que uma tradição bíblica criacionista emerge como reposta à origem da humanidade. Neste cenário, recuperamos a ideia enunciada no Gênesis:

Então o SENHOR Deus fez com que o homem caísse num sono profundo. Enquanto ele dormia, Deus tirou uma das suas costelas e fechou a carne naquele lugar. Dessa costela o SENHOR formou uma mulher e a levou ao homem. Então o homem disse: "Agora sim! Esta é carne da minha carne e osso dos meus ossos. Ela será chamada de 'mulher' porque Deus a tirou do homem." É por isso que o homem deixa o seu pai e a sua mãe para se unir com a sua mulher, e os dois se tornam uma só pessoa (BÍBLIA, Gênesis, 2, 21-24).

A retomada feita pelo picho permite agora o preenchimento das formas genéricas aí contidas, a saber, os pronomes "eu" e "você", bem como o demonstrativo "sua" que determina "costela": "Cabe às mulheres lembrar-se de sua origem; não vangloriar-se de sua delicadeza e pensar, afinal, que têm origem num osso acessório cuja beleza se limita à que Deus houve por bem lhe conferir" (BOSSUET, apud PERROT, 2007, p. 23).

Se é por referência ao saber bíblico que, no espaço do interdiscurso, o criacionismo emerge como "aquilo a que a pichação responde", é desse lugar que advém a figura do homem como referência para "sua" e "você", assim como da mulher como referência ao "eu" que nega uma suposta origem na costela masculina. Os termos "eu" e "você" exigem o preenchimento imediato do primeiro por mulher e do segundo por homem.

Para além dessa referência ao interdiscurso (o criacionismo fundamentado pela Bíblia), que garante o "sabe-se quem é "eu" e o "sabe-se quem é 'você"”, observamos o funcionamento da metonímia como figura que identifica - para subverter, em certo sentido - os papéis do homem e da mulher. No contexto do picho, "costela" é a parte que se estende a um todo "homem" e se opõe a outra parte "útero" que se estende a outro todo "mulher". Essa leitura sustenta-se ainda pela referência necessária do dêitico "sua" a "homem" no quadro do criacionismo bíblico: o demonstrativo faz irromper a figura masculina, pois, no Gênesis, é da costela masculina que se trata.

Isto acrescenta um ponto importante a respeito dos seres que poderiam derivar do útero: há um efeito de sentido de exclusão dos seres que não são homens e isso se dá como reforço a uma luta localizada entre mulher $\mathrm{x}$ homem ou entre uma posição libertária e outra conservadora. Nesse sentido, parecem não funcionar, para efeito de sustentação desta formulação, correlatos do tipo:

(1) Eu não vim da sua costela. Você veio da minha cabeça.

(2) Eu não vim da sua costela. Você veio da minha vontade.

(3) Eu não vim da sua costela. Você veio das minhas costas.

Cumpre destacar ainda que o lugar de origem inicial, advindo do mito bíblico, tem como contra-argumento uma definição de origem pautada na ciência. 
Enquanto, "vir da costela" é imaginário, mitológico, sobrenatural, "vir do útero" é real, concreto e, principalmente, natural. O efeito de sentido aí construído é o de que a suposta "superioridade do homem sobre a mulher", sustentada pelo discurso machista conservador, pauta-se em um "devaneio criacionista" inverossímil, enquanto o da "superioridade da mulher sobre o homem", sustentada por um discurso de tipo libertário-progressista, assenta-se em uma verossimilhança atestada pela ciência. $\mathrm{O}$ aspecto revolucionário - majoritariamente delineador deste picho - implicado na negação da religião e afirmação da ciência como elemento equilibrador dos sexos destaca-se, mas deixa ainda rastros da "boa e velha" maternidade como função pré-admitida da mulher.

Nessa mesma linha da "valorização da mulher como mãe", temos o seguinte picho:

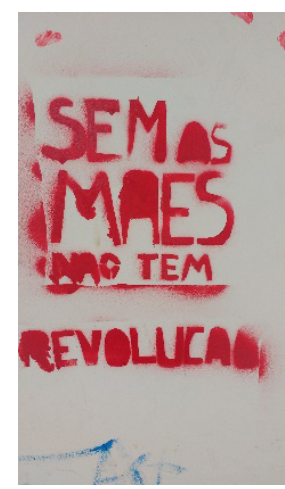

Figura 3. Sem as mães não tem revolução

Fonte: Foto de Patrícia Bucioli

O caráter da expressão "Sem as mães" é ambíguo face ao restante da formulação: (i) "Sem as mães" pode significar "sem a função geradora do sujeito materno"; (ii) "Sem as mães" pode significar "sem a educação dada pelas mães"(iii) "Sem as mães" pode significar "sem a participação (presença) das mães". Parafraseando os três cenários, teríamos:

(i) Se as mães não gerarem os revolucionários... (conservadorismo)

(ii) Se as mães não formarem os revolucionários... (misto)

(iii) Se as mães não participarem da revolução... (contravenção)

Para o primeiro efeito de sentido, é possível assinalar o mesmo enunciado conservador que atravessa as duas formulações anteriores, a saber: "toda mulher é/deve ser mãe". A revolução, nestes termos, fica condicionada ao nascimento, à origem dos revolucionários. Recuperando a estrutura da primeira formulação analisada mais acima ("Toda mulher é mãe de todos os homens"), poderíamos parafrasear esta última como "Toda mulher é mãe de todos os revolucionários", por exemplo. O segundo efeito de sentido transita entre duas posições 
ideológicas distintas, a conservadora e a contraventora. Por um lado, "formar um revolucionário" é tarefa que rompe um horizonte de expectativa na medida em que associa o ato de educar a um "educar para subverter", para questionar, para problematizar; por outro lado, há também o efeito de sentido de que "filho deve ser educado pela mãe". Como toda mãe pressupõe um pai, fica subentendido que o pai está, de certa forma, por retomada de uma posição conservadora, desobrigado desta formação. Por fim, "Sem as mães" também carrega um aspecto puramente contraventor - já que, a rigor, não se espera, no âmbito conservador dos papéis designados à maternidade, que as mães participem de revoluções - no sentido de participação materna na revolução.

A segunda parte da formulação constrói um efeito de referência. "Revolução" funciona como pré-construído, o "sabe-se o que é". Ambiguamente, o termo, normalmente associado à contravenção, joga com o conservadorismo. Por um lado, como signo da capacidade geradora, "Sem as mães" quebra com um horizonte de expectativa conservador ao colocar a mãe na cena revolucionária. Nesse sentido, é revolucionário contrariar valores que poderiam ser parafraseados como: "Mãe tem que ficar em casa cozinhando e cuidando dos filhos". Por outro lado, a ideia de "mãe educar para a revolução" e "mãe participar da revolução" implica que a mulher "tem de ser mãe para...", ou seja, volta-se inconscientemente à velha ideia de que "ser mulher implica ser mãe".

\section{CONCLUSÃO}

Estamos habituados a ouvir que a pichação é a voz daqueles que não se sentem parte do espaço no qual estão inseridos. Nesse sentido, ela é constantemente associada - isso faz parte, efetivamente, de sua condição no imaginário social - à marginalidade e a contravenção. Seu caráter ilegal no discurso jurídico reforça essa condição de existência. Seus atores querem que assim o seja, isto é, há uma espécie de desejo de ilegalidade que garante o picho como algo fora da norma.

No entanto, a partir do que foi discutido neste artigo, concluímos que essa é apenas uma das faces da moeda. Ao lado desse imaginário da pichação como prática de resistência, caminha a possibilidade sempre aberta pela opacidade da língua de que o picho possa ser também aquilo de que pretende se distanciar, isto é, ele pode ser também normativo e conservador. A meia distância, como inscrição estilizada nas paredes públicas e privadas, a "rabisqueira" é subversiva, mas de perto, na materialidade visível do texto que se concretiza, as coisas não são assim tão simples.

Pudemos observar que em uma das temáticas recorrentes nas pichações - os diferentes papéis que a mulher pode ocupar na sociedade (PERROT, 2007) - o que se sabe e o que se diz sobre as mulheres nessa atmosfera contraventora do picho é, não raro, um misto de resistência e de reprodução da velha memória da mulher como mãe. Nesse sentido, este artigo levantou uma questão e procurou oferecer uma resposta possível a ela: "Em que medida se transgride quando se picha?" A conclusão a que chegamos é: transgride-se quando se pratica o picho, mas no 
que diz respeito ao texto pichado, isso nem sempre é verificável de modo tão transparente. Assim, entendemos que contrariar valores não está necessariamente ligado a práticas que contrariam leis. Muitas vezes, como demonstramos aqui, contrariar as leis pode ser também e ao mesmo tempo - no produto final do ato contraventor - reproduzir valores conservadores e machistas.

\section{REFERENCIAS}

ARISTÓTELES. Retórica. Tradução de Edson Bini. São Paulo: EDIPRO, 2011.

BÍBLIA, A. T. Gênesis. In: Bíblia: nova tradução na linguagem de hoje. Tradução de João João Ferreira de Almeida. Barueri: Sociedade Bíblica do Brasil, 2013. pp. 3-57

COURTINE, J-J. Análise do discurso político: o discurso comunista endereçado aos cristãos. Tradução de Cristina de Campos Velho Birck et. al. São Carlos: EDUFSCAr, 2009.

COURTINE, J-J. (1999). "O chapéu de Clémentis. Observações sobre a memória e o esquecimento na enunciação do discurso politico". Traduzido por Marne Rodrigues de Rodrigues. In: INDURSKY, Freda \& FERREIRA, Maria Cristina Leandro (org.). Os múltiplos territórios da Análise do Discurso. São Paulo: Sagra Luzzatto. pp. 15-22.

GITAHY, Celso. O que é graffiti. São Paulo: Brasiliense, 1999.

ORLANDI, Eni. Cidade dos sentidos. Campinas: Pontes, 2004.

PÊCHEUX, Michel. Semântica e Discurso: uma crítica à afirmação do óbvio. Tradução de Eni Orlandi. 3. ed. Campinas: Editora da Unicamp, 1997.

PÊCHEUX, Michel. O discurso: estrutura ou acontecimento. Tradução de Eni Orlandi. 7. ed. Campinas: Pontes, 2015.

PERROT, Michelle. Minha história das mulheres. Tradução de Angela M. S. Côrrea. São Paulo: Contexto, 2007.

SOUZA, David da Costa Aguiar de. Pichação carioca: etnografia e uma proposta de entendimento. 2007. 122 f. Dissertação (Mestrado) - Curso de Programa de Pós-Graduação em Sociologia e Antropologia, Instituto de Filosofia e Ciências Sociais, Universidade Federal do Rio de Janeiro, Rio de Janeiro, 2007. Disponível em: $<$ http://comunidadesegura.org.br/files/pichacao carioca. pdf>. Acesso em: 27 jun. 2017.

Recebido: 21/09/2018

Aceito: $12 / 02 / 2019$

Publicado: 13/02/2019 